\title{
Discovery Model of Growing Potential Opportunity in E-Commerce Platform Based on Social Network and Entrepreneur Trait
}

\author{
Manlin Wang ${ }^{1, a}$, Shaowei Xia ${ }^{1, b}$, Qingguo Wang ${ }^{1, c}$ \\ ${ }^{1}$ School of Management, Wuhan University of Technology, Wuhan 430000, China; \\ a441200115@qq.com, 'ludasw@126.com, cwqg1997@163.com
}

\begin{abstract}
Keywords: e-commerce platform; growing potential opportunity; social network; entrepreneur trait; content analysis method; structural equation modeling.
\end{abstract}

\begin{abstract}
This article first defines the connotation of growing potential opportunity and social network of e-commerce platform, and analyzes the impact of social network on searching growing potential opportunity information. On this basis, this paper puts forward the view that social network affects the growing potential opportunity discovery in e-commerce platform by the way of affecting the process of information searching. Secondly, this paper analyzes the structural features of social network form several dimension, and introduces entrepreneur trait as the adjustment factor in the process of discovering growing potential opportunity in e-commerce platform. On the basis of discussing the impact of the various dimensions on growing potential opportunity discovery, this paper proses related research hypothesizes and builds the discovery model of growing potential opportunity in e-commerce platform based on social network and entrepreneur trait. Finally, this study uses content analysis methodology and SEM (Structural Equation Modeling) to empirical research and gets the conclusion that, in the condition of information asymmetry constraint, the social network affect he growing potential opportunity discovery in e-commerce platform by the way of helping it to get more information and to enhance its capability of absorbing information from external environment.
\end{abstract}

\section{Introduction}

With the rapid development of global network economy, the e- commerce platform that supporting the operation of e- commerce is expanding, while the competition between e-commerce platforms is becoming increasingly fierce, and it becomes the inevitable pursuit of excellence for the e-commerce platforms to catch the initiative and lead the trend in the highly competitive environment. Facing the homogenization of competition, diversification of technology, transient of perception and personalized demand of customer, e-commerce platforms must be urgent to seek and find their own growth opportunities and strive for the predominance.

This study focuses on the online retailers that not only include Jingdong Mall, dangdang.com etc. which are built and controlled by the part of seller, but also include Tmall, Paipai etc. which are third party e-commerce platform.

\section{Literature and Theory}

Social Network of E-Commerce Platform. Social network is one of the important information sources for the entrepreneurs to search information, and it is a relationship network that connects the enterprise with other organizations or individuals through specific business activities. The complex and diverse social relationship of the network members provides various kinds of information for e-commerce platform operators, and they should identify the valuable information to develop opportunities that are good to the growth and development of enterprise. In this paper, the scope of the social network of the e-commerce platform is defined as: suppliers, partners, technology alliance, customers, competitors and institutes of government and research. 
The division of social network dimension is an important problem in the field of research on the application of social network, and some scholars have done fruitful research. This paper summarizes the main views of the research on social network dimension, as shown in Table 1.

Table 1: Main Views of Social Network Dimension

\begin{tabular}{|c|c|c|}
\hline Research Dimension & Research Content & Scholars \\
\hline $\begin{array}{c}\text { network scale, dissimilarity, } \\
\text { construction and management ability, } \\
\text { network density }\end{array}$ & $\begin{array}{c}\text { the impact of social capital embedded in the social } \\
\text { network on the competitiveness of the cluster } \\
\text { enterprises }\end{array}$ & Li Shufen [1] \\
\hline $\begin{array}{c}\text { network centrality, trust between } \\
\text { network nodes, connection strength, } \\
\text { diversity of network nodes }\end{array}$ & $\begin{array}{l}\text { the impact of social network on the innovation } \\
\text { capability of the cluster enterprise from }\end{array}$ & $\begin{array}{c}\text { Xu Dengfeng } \\
\text { [2] }\end{array}$ \\
\hline $\begin{array}{c}\text { network density, reciprocal and } \\
\text { connection strength, relationship } \\
\text { stability }\end{array}$ & the relationship between network nodes & Li Zhigang [3] \\
\hline $\begin{array}{l}\text { network structure, network regularity, } \\
\text { capital embedded in network }\end{array}$ & $\begin{array}{c}\text { different relationship between the network } \\
\text { characteristics influence the capability of } \\
\text { explanation }\end{array}$ & Davern [4] \\
\hline $\begin{array}{c}\text { analysis of network position, analysis of } \\
\text { network relation }\end{array}$ & $\begin{array}{l}\text { network position analyzes the node's position in } \\
\text { network, and network relation analyzes the } \\
\text { intimacy of relationship }\end{array}$ & Burt [5] \\
\hline $\begin{array}{c}\text { network intermediary centricity and } \\
\text { network centricity }\end{array}$ & the difference between them to measure centricity & Freeman [6] \\
\hline
\end{tabular}

Summarizing the previous research results and combining with the structural features of social network of e-commerce platform, this paper uses five dimensions to describe the social network of the e-commerce platform, namely network scale, network centrality, structural hole, relationship strength and relationship stability.

Entrepreneur Trait. Personal traits of e-commerce platform operators have important influence on opportunity identification for enterprises. In the process of discovery about growing potential opportunity of e-commerce platform, entrepreneur trait plays an important role in identifying and evaluating the opportunity information because no matter how much valuable opportunity information the e-commerce platform got, the information must be analyzed and handled by the entrepreneur so as to develop growth opportunity. This paper mainly discusses the impact of entrepreneur trait on the discovery about growing potential opportunity of the e-commerce platform, and focuses on entrepreneur's priori knowledge and innovation capability.

\section{Hypothesis}

Network Scale. In the process of discovery about growing potential opportunity of e-commerce platform, the more connection with other organizations or individuals, the more nodes are embedded in the social network and the size is more extensive, the more opportunity information can be provided to the e-commerce platform.

Hypothesis 1: The network scale has positive effect on the discovery about growing potential opportunity of e-commerce platform.

Network Centrality. The closer to the center it is, e-commerce platform will get more information about the market demand, and it makes the direction of opportunity discovery much clearer for e-commerce platform.

Hypothesis 2: The network centrality has positive effect on the discovery about growing potential opportunity of e-commerce platform. 
Structural Hole. Burt's study on entrepreneurial process [5] indicated that the nodes that were at the position of structure hole in the social network were more likely to get the latest news and business information because they played the role of connecting other nodes who had heterogeneous resource.

Hypothesis 3: The structural hole has positive effect on the discovery about growing potential opportunity of e-commerce platform.

Relationship Strength. Strong relationship helps the e-commerce platform obtain information from its social network at relatively low cost. Hansen [7] pointed out that weak ties can transfer new knowledge and information to the enterprise, and strong ties can provide accurate information the enterprise.

Hypothesis 4: The relationship strength has positive effect on the discovery about growing potential opportunity of e-commerce platform.

Relationship Stability. Lasting and stable social network relationship makes contribution to the knowledge sharing between network members, and it makes the network members more willing to share their valuable information with other others.

Hypothesis 5: Relationship stability has positive effect on the discovery about growing potential opportunity of e-commerce platform.

Priori Knowledge. Shane's study [8] indicated that prior knowledge provided basic knowledge for people, which would help people identify specific opportunities from certain information.

Hypothesis 6: Priori knowledge has positive effect on the discovery about growing potential opportunity of e-commerce platform.

Innovation Capacity. Creative people can analyze and process the information in many ways, and their novel ideas, insights, sharp observation ability make contribution to the success of opportunity discovery.

Hypothesis 7: Innovation capability has positive effect on the discovery about growing potential opportunity of e-commerce platform.

\section{Methods}

Control Variables. In this study, there is an endogenous latent variable (Opportunity Discovery), two exogenous latent variables (Social Network, Entrepreneur Trait). And for simplifying the study, we establish the number of discovered opportunities $\left(Y_{1}\right)$ and the number of seized opportunities $\left(Y_{2}\right)$ as the observational variables of Opportunity Discovery, and define network scale $\left(X_{1}\right)$, network centrality, $\left(X_{2}\right)$ structural hole $\left(X_{3}\right)$, relationship strength $\left(X_{4}\right)$ and relationship stability $\left(X_{5}\right)$ as the observational variables of Social Network, and let priori knowledge $\left(X_{6}\right)$, innovation capacity $\left(X_{7}\right)$ as the observational variables of Entrepreneur Trait.

Assuming that the number of discovered opportunities mentioned in one sample literature is $N_{1}$ and $N_{2}$ represents the number of seized opportunities mentioned in one sample literature, we set the value of $Y_{1}$ and $Y_{2}$ following below formula:

$$
\begin{aligned}
& Y_{1}=\left\{\begin{array}{lc}
N_{1} & \left(0 \leq N_{1}<10\right) \\
10 & \left(N_{1} \geq 10\right)
\end{array},\right. \\
& Y_{2}=\left\{\begin{array}{cc}
N_{2} & \left(0 \leq N_{2}<10\right) \\
10 & \left(N_{2} \geq 10\right)
\end{array},\right.
\end{aligned}
$$

In the formula, $N_{1}$ is greater than or equal to $N_{2}$, namely $N_{1} \geq N_{1}$, and both of $N_{1}$ and $N_{2}$ are all integers. Therefore, the range of $Y_{1}$ and $Y_{2}$ is $[0,10]$..

Data \& Metrics. We retrieved about 290 study cases in all, and basing on the practical requirements this paper selected about 166 cases as the analysis samples. This study used content analysis method to extract relevant data from the sample cases to analyze, and we took the entire 
content of a document as a unit of analysis for the key words and key information which may appear throughout the literature. Basing on the practical requirements, we took social network and entrepreneur trait as categories of analysis and selected the factors that had effect on growing potential opportunities discovery of e-commerce platform as units of analysis. To ensure the completeness and credibility of the analysis units, this paper extracted the key words that are similar to these factors from each literature.

Validity and Reliability Test. Table 2 describes correlations between variables. KMO and Bartlett's Test for the sample data is shown in Table 3. Table 3 shows that the KMO is 0.812, and the Bartlett's probability of significant is less than 0.01, implying that the sample data is suitable to be used for factor analysis.

Table 2: Correlations

\begin{tabular}{|c|c|c|c|c|c|c|c|c|c|}
\hline & $\begin{array}{c}\text { network } \\
\text { scale }\end{array}$ & $\begin{array}{c}\text { network } \\
\text { centrality }\end{array}$ & \begin{tabular}{|c|} 
structura \\
1 \\
hole
\end{tabular} & $\begin{array}{c}\text { relationship } \\
\text { strength }\end{array}$ & $\begin{array}{c}\text { relationshi } \\
\mathrm{p} \\
\text { stability }\end{array}$ & $\begin{array}{c}\text { priori } \\
\text { knowledg } \\
\text { e }\end{array}$ & $\begin{array}{c}\text { innovation } \\
\text { capacity }\end{array}$ & $\begin{array}{c}\text { discovered } \\
\text { opportunities }\end{array}$ & $\begin{array}{c}\text { seized } \\
\text { opportunities }\end{array}$ \\
\hline $\begin{array}{c}\text { network } \\
\text { scale }\end{array}$ & 1 & $.300 * *$ & $.515^{* *}$ & $.501 * *$ & $.420 * *$ & $.185^{*}$ & $.259 * *$ & $.663^{* *}$ & $.686^{* *}$ \\
\hline $\begin{array}{c}\text { network } \\
\text { centrality }\end{array}$ & $.300 * *$ & 1 & $.588 * *$ & $.522 * *$ & $.403^{* *}$ & .118 & $.225^{* *}$ & $.640 * *$ & $.538 * *$ \\
\hline $\begin{array}{c}\text { Structural } \\
\text { hole }\end{array}$ & $.515^{* *}$ & $.588 * *$ & 1 & $.577 * *$ & $.481^{* *}$ & $.170 *$ & $.274^{* *}$ & $.726 * *$ & $.672 * *$ \\
\hline $\begin{array}{l}\text { relationship } \\
\text { strength }\end{array}$ & $.501^{* *}$ & $.522 * *$ & $.577 * *$ & 1 & $.713^{* *}$ & .126 & $.253^{* *}$ & $.707^{* *}$ & $.618^{* *}$ \\
\hline $\begin{array}{c}\text { relationship } \\
\text { stability }\end{array}$ & $.420 * *$ & $.403^{* *}$ & $.481 * *$ & $.713^{* *}$ & 1 & .090 & $.191 *$ & $.570 * *$ & $.507 * *$ \\
\hline $\begin{array}{c}\text { priori } \\
\text { knowledge }\end{array}$ & $.185^{*}$ & .118 & $.170^{*}$ & .126 & .090 & 1 & $.661^{* *}$ & $.298 * *$ & $.511^{* *}$ \\
\hline $\begin{array}{c}\text { innovation } \\
\text { capacity }\end{array}$ & $.259 * *$ & $.225 * *$ & $.274^{* *}$ & $.253 * *$ & $.191 *$ & $.661^{* *}$ & 1 & $.384^{* *}$ & $.484^{* *}$ \\
\hline $\begin{array}{c}\text { discovered } \\
\text { opportunities }\end{array}$ & $.663 * *$ & $.640 * *$ & $.726^{* *}$ & $.707^{* *}$ & $.570 * *$ & $.298 * *$ & $.384^{* *}$ & 1 & $.917^{* *}$ \\
\hline $\begin{array}{c}\text { seized } \\
\text { opportunities }\end{array}$ & $.686^{* *}$ & $.538 * *$ & $.672 * *$ & $.618 * *$ & $.507 * *$ & $.511^{* *}$ & $.484^{* *}$ & $.917^{* *}$ & 1 \\
\hline
\end{tabular}

**. Correlation is significant at the 0.01 level (2-tailed). *. Correlation is significant at the 0.05 level (2-tailed).

Table 3: KMO and Bartlett's Test

\begin{tabular}{|c|c|c|}
\hline Kaiser-Meyer-Olkin Measure of Sampling Adequacy. & .812 \\
\hline \multirow{3}{*}{ Bartlett's Test of Sphericity } & Approx. Chi-Square & 1076.434 \\
\cline { 2 - 3 } & $\mathrm{df}$ & 36 \\
\cline { 2 - 3 } & Sig. & .000 \\
\hline
\end{tabular}

Wet tested the credibility of the sample data with SPSS17.0 software, as shown in Table 4. From Table 4, we can see that the two Cronbach's Alphas, which are more than 0.7, are 0.802 and 0.776 , and the minimum of the factor loading is 0.683 , which show that the sample data is of high credibility. 
Table 4: Reliability Statistics

\begin{tabular}{|c|c|c|c|}
\hline & Dimension & Factor Loading & Cronbach's Alpha \\
\hline \multirow{4}{*}{ social network } & network scale & .683 & \multirow{3}{*}{} \\
\cline { 2 - 3 } & network centrality & .711 & \multirow{2}{*}{.802} \\
\cline { 2 - 3 } & structural hole & .800 & \multirow{2}{*}{.802} \\
\cline { 2 - 3 } & relationship strength & .846 & \\
\cline { 2 - 3 } & relationship stability & .758 & \multirow{2}{*}{.776} \\
\hline \multirow{2}{*}{ entrepreneur trait } & priori knowledge & .920 & \multirow{2}{*}{.776} \\
\cline { 2 - 3 } & innovation capacity & .857 & \\
\hline
\end{tabular}

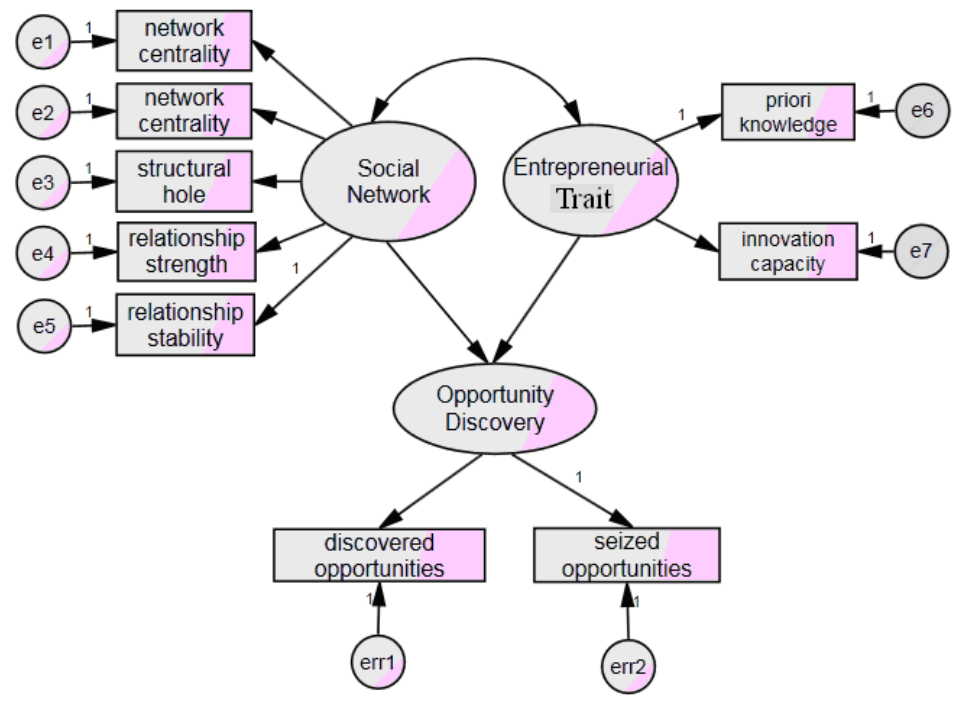

Figure 1: Path Graph of Initial SEM

Model Specification. Combined with the concept model of growing potential opportunities discovery in e-commerce platform, this paper draw the initial path graph of SEM, as shown in Fig. 1.

In the model, the ovals represent latent variables, rectangles represent observational variables, and the small circle indicates observational variable residual. We can see from the graph that there is an endogenous latent variable (Opportunity Discovery), two exogenous latent variables (Social Network, Entrepreneur Trait) and nine observational variables (network scale, network centrality, structural hole, relationship strength, relationship stability, priori knowledge, innovation capacity, discovered opportunities and seized opportunities).

\section{Result}

Initial model fitting and evaluation. This study selected several commonly used fitting indices to evaluate the model fitting, as shown in Table 5.

Table 5: Initial Model Fit

\begin{tabular}{|c|c|c|c|c|}
\hline Fit Index & Fitting Well & Fitting Acceptable & Index Value & Result Evaluation \\
\hline$\chi^{2} / D F$ & $\chi^{2} / D F<3$ & $3 \leq \chi^{2} / D F<5$ & 6.769 & $\begin{array}{c}\text { more than 5, } \\
\text { unacceptable }\end{array}$ \\
\hline GFI & GFI $>0.9$ & GFI $>0.8$ & 0.827 & acceptable \\
\hline TLI & TLI $>0.9$ & TLI $>0.8$ & 0.805 & acceptable \\
\hline CFI & CFI $>0.9$ & CFI $>0.8$ & 0.865 & acceptable \\
\hline RMSEA & RMSEA $<0.08$ & $0.08 \leqslant$ RMSEA $<0.10$ & 0.187 & $\begin{array}{c}\text { more than 0.1, } \\
\text { unacceptable }\end{array}$ \\
\hline
\end{tabular}


From table 5, we can see that GFI, TLI and CFI are 0.827, 0.805 and 0.865 , which indicates that their fitting results are acceptable, while $\chi^{2} / D F$ and RMSEA are respectively 6.769 and 0.187 , both of which are beyond the acceptable scope of fitting. Therefore, the model fitting result is not very satisfactory, and the initial model needs to be adjusted and modified.

Model Modification. According to the Modification Indices (MI) from the output view, we add several key paths which can make $\chi^{2} / D F$ change significantly, as shown in Table 6.

Table 6: Modification Indices

\begin{tabular}{|c|c|c|}
\hline Path & M.I. & Par Change \\
\hline err1<--> e6 & 27.035 & -.3445 \\
\hline err2<-->e7 & 4.040 & .081 \\
\hline e1<-->err1 & 6.762 & -.188 \\
\hline e3<-->e2 & 7.200 & .661 \\
\hline e2<-->e1 & 11.645 & -1.130 \\
\hline e5<-->e4 & 42.017 & .702 \\
\hline
\end{tabular}

After adding the six key paths and importing data into AMOS21.0 software, we estimate the modified model and output the estimated regression weights as shown in Table 7 and the commonly used fitting indices as shown in Table 8.

Table 7: Regression Weights: Estimate for Modified SEM

\begin{tabular}{|c|c|c|c|c|}
\hline Path & $\begin{array}{c}\text { Unstandardized } \\
\text { Estimate }\end{array}$ & C.R. & $\mathrm{P}$ & $\begin{array}{c}\text { Standardize } \\
\mathrm{d} \\
\text { Estimate }\end{array}$ \\
\hline Opportunity Discovery<--Social Network & 1.273 & 8.654 & $\begin{array}{c}* * \\
*\end{array}$ & .843 \\
\hline Opportunity Discovery <--- Entrepreneur Trait & .107 & 3.568 & $\begin{array}{c}* * \\
*\end{array}$ & .298 \\
\hline relationship stability <---Social Network & 1.000 & & & .579 \\
\hline relationship strength <---Social Network & 1.361 & 10.504 & $\begin{array}{c}* * \\
*\end{array}$ & .713 \\
\hline structural hole <---Social Network & 1.778 & 7.623 & $\begin{array}{c}* * \\
*\end{array}$ & .734 \\
\hline network scale <---Social Network & 2.320 & 7.500 & $\begin{array}{c}* * \\
*\end{array}$ & .743 \\
\hline network centrality <---Social Network & 2.082 & 7.018 & $\begin{array}{c}* * \\
*\end{array}$ & .641 \\
\hline priori knowledge <---Entrepreneur Trait & 1.000 & & & .671 \\
\hline innovation capacity <--- Entrepreneur Trait & .235 & 3.873 & $\begin{array}{c}* * \\
*\end{array}$ & .778 \\
\hline discovered opportunities<---Opportunity Discovery & 1.226 & 24.488 & $\begin{array}{c}* * \\
*\end{array}$ & .978 \\
\hline seized opportunities<---Opportunity Discovery & 1.000 & & & .951 \\
\hline
\end{tabular}

Table 8: Modified Model Fit

\begin{tabular}{|c|c|c|}
\hline Fit Index & Index Value & Result Evaluation \\
\hline$\chi^{2} / D F$ & 1.548 & well \\
\hline GFI & .963 & well \\
\hline TLI & .981 & well \\
\hline CFI & .990 & well \\
\hline RMSEA & .058 & well \\
\hline
\end{tabular}




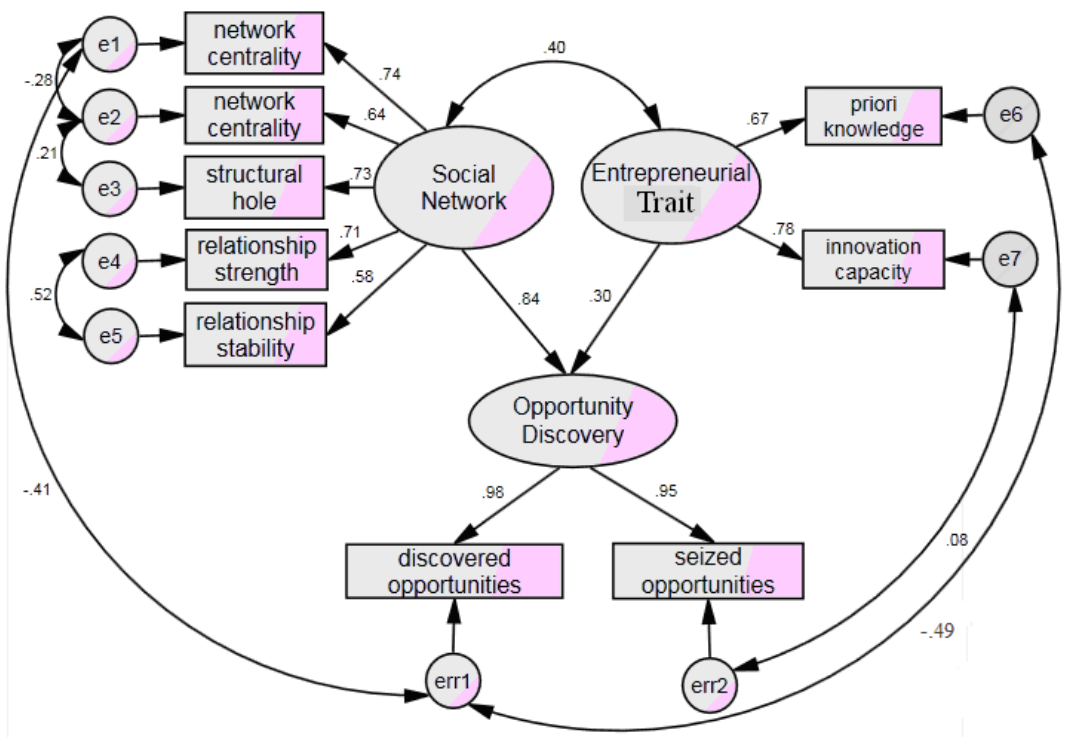

Figure 2: Path Graph with Regression Weights of Modified SEM

Confirmed SEM. We get the path graph with regression weights of modified model with the AMOS21.0 software, as shown in Fig. 2.

\section{Summary}

On the whole, this paper validates that the social network and entrepreneur trait have positive effects on the growing potential opportunity discovery of e-commerce platform, and the seven hypotheses have been validated. While the social network and entrepreneur traits have different influence to the process of opportunity discovery. Social network has larger impact than entrepreneur trait on the discovery about growing potential opportunity of e-commerce platform. And this proves that, in the process of opportunity discovery, the e-commerce platform should obtain plenty of opportunity information through its social network first and then the entrepreneurs apply their priori knowledge and innovation capacity to handle and analyze the information, and thereby to identify the growth opportunities.

The path coefficients of network scale, network centrality, structural hole, relationship strength, relationship stability to social network are all above 0.5 , implying the important impact of social network on searching opportunity information. And what's more, the influence coefficient of network scale, structural hole and relationship strength are more than 0.7 , indicating that the enterprise can get more information from external environment by expanding its social network scale. The network nodes which are at the position of structural hole, play a role of bridge in connecting other nodes, contributing to obtain more multipartite heterogeneous resources for the enterprise, which will help it grasp advantages of information superiority.

Entrepreneur trait plays a key role in process of discovery about growing potential opportunity of e-commerce platform. The priori knowledge could influence entrepreneurs on analyzing and identifying the external information, and the innovation capacity is a critical factor for entrepreneurs to develop opportunities successfully.

\section{References}

[1] Li Shufen. Research on the impact of Entrepreneurial social Capital to Competitive Advantage of Cluster Enterprise [D].Jilin University (2011)

[2] Xu Dengfeng. Study on Innovation Mechanism of Cluster Enterprise Based on Social Network [D].Tianjin University (2010) 
[3] Li Zhigang. Research on the Innovation Mechanism and Innovation Performance of Industry Clusters Based on Network Structure [D]. University of Science and Technology of China (2007)

[4] Davern \& Micheal. Social network and economic sociology: purposed research agenda for a more complete social science [J].American Journal of Economics and Sociology (1997)

[5] Burt, R. S. Structural holes: The social structure of competition [M]. Cambridge, MA: Harvard University Press (1992)

[6] Freeman C. Network of innovators: a synthesis of research issues. Research Policy (1991)

[7] Hansen M. T. The search-transfer problem: The role of weak ties in sharing knowledge across organization subunits. Administrative Science Quarterly (1999)

[8] Shane, S. Prior knowledge and the discovery of entrepreneurial opportunities [J]. Organization Science (2000) 